\title{
Enhanced Conductivity and Ion Exchange Capacity of Chitosan Membranes through Modification with Lithium for Lithium Polymer Battery Application
}

\author{
S. N. ASNIN ${ }^{1}$, WAHAB $^{2}$, D. PERMANA ${ }^{3}$, L. O. AHMAD ${ }^{1}$, S. H. SABARWATI ${ }^{1}$, L. O. A. N. \\ RAMADHAN $^{1}$ \\ ${ }^{1}$ Department of Chemistry, Universitas Halu Oleo, Kendari \\ ${ }^{2}$ Department of Mining Engineering, Universitas Halu Oleo, Kendari \\ ${ }^{3}$ Department of Agriculture, University of Sembilanbelas November, Kolaka \\ INDONESIA \\ *Corresponding author e-mail: la.ode.ahmad@gmail.com http://www.uho.ac.id
}

\begin{abstract}
Modification of chitosan membranes using lithium has been developed. The chitosan membranes were prepared from several deacetylation degree of chitosan. The effect of the deacetylation degree towards an ion conductivity properties of the chitosan membranes, effect of concentration of chitosan-lithium membranes and capability of ionic conductivity as an electrolyte polymer for lithium polymer battery application were studied. The membranes were prepared by the solvent evaporation method. Fourier transform-infrared spectroscopy showed a peak at $1573.8 \mathrm{~cm}^{-1}$ correspond to the ionic interaction between lithium salt with $\mathrm{NH}_{2}$ groups from chitosan. The scanning electron microscopy analysis showed high pore density and rigidity of chitosan membrane microstructure, meanwhile chitosan-lithium membranes have clusters which indicated the deposition of lithium nitrate salt at chitosan polymer chains. The water uptake capacity of the chitosan-lithium membranes was higher than that of the chitosan membrane. The tensile strength analysis showed that the chitosan-lithium membranes was more elastic than the chitosan membranes. Chitosan membrane conductivity and ion exchange capacity are $1.70 \times 10^{-2}{\mathrm{~S} . \mathrm{cm}^{-1}}$ and $2.11 \mathrm{~m}_{\mathrm{eq}} \cdot \mathrm{g}^{-1}$, while the conductivity after adding lithium salt increased to $8.53 \times 10^{-2} \mathrm{~S}_{\mathrm{cm}} \mathrm{cm}^{-1}$ and $3.16 \mathrm{~m}_{\mathrm{eq}} \cdot \mathrm{g}^{-1}$, respectively. The result indicated that modification of chitosan by the addition of lithium salt increased the membrane ionic conductivity and ion exchange capacity values. This solid polymer electrolyte membrane has a potential to be used as a polymer electrolyte in lithium battery.
\end{abstract}

Key-Words: - battery, chitosan, conductivity, deacetylation, exchange capacity, lithium, membrane

\section{Introduction}

Electricity is one form of energy and can very easily converted into other form of energy such as heat or mechanical energy. Electrical energy can be produced from a chemical reaction. An electrochemical energy system can produce electrical energy from a chemical reaction. Some examples of electrochemical system are fuel cells, capacitors and batteries [1].

The battery is an electrochemical cell circuit composed of cathode, anode, electrolyte, and a conductor capable of generating electrical energy with a certain potential. The batteries are common in portable tools that today is lithium batteries. Initially, the electrolyte lithium batteries used in the form of a solution, but it gives rise to various disadvantages such as less practical, easy to leak, and easily corroded. Because of these weaknesses, the electrolyte in liquid form is becoming obsolete and switch on the solid polymer electrolyte as an ionic conductor polymer battery that called lithium/lithium polymer of LiPo.

Battery of lithium polymer is using dry polymer electrolyte that is shaped like a thin film layer. The film layer is structured in layers between the anode and cathode resulting ion exchange [2]. The type of polymer that has been used as the matrix that was nafion [3], PMM (polymethyl methacrylate) [4], and PVDF (Polyvinyl Diflourida) [5].

Chitosan is a natural polymer chitin derivative that can be used as a proton conducting membrane [6]. But under normal circumstances, chitosan has low electrical conductivity because chitosan can not be immobilized under the influence of an electric field to generate a proton conductor [7]. Chitosan membrane conductivity is $2.88 \times 10^{-6}{\mathrm{~S} . \mathrm{cm}^{-1}}^{\text {[8] }}$. 
Some researchers added plasticizer and salt to increase the conductivity of chitosan membrane such as lithium nitrate [7], succinic anhydride and lithium perchlorate [8], poly(ethylene glycol) and lithium perchlorate [9], fatty acid and lithium acetate [10], lithium perchlorate and choloauric acid [11]. Presence of plasticizer will enhance salt dissolution and mobile species formation [10]. However, plasticizer addition reduces the mechanical strength and thermal stability [12] [13].

In this study, deacetylation degree of chitosan was increased to allow salt dissolution. The ability of chitosan to deliver ion depends on the magnitude of the degree of deacetylation. The increasing of deacetylation degree leads to better solubility of chitosan in aqueous organic acids, therefore chitosan can be protonated polyelectrolyte through group $\mathrm{NH}_{2}$ [10].

In order to produce chitosan with high deacetylation degree without decreasing the molecular weight can be prepared by repeated deacetylation [14]. Based on the previous research [15], chitosan with variation of deacetylation degree (DD) was modified by lithium nitrate to investigate the ionic conductivity and ion exchange capacity of the membrane. Basically, the first part of this paper discusses the introduction of the lithium polymer membranes especially chitosan membranes. In the second part will be introduced materials and methods. Some measurements and characterizations will be introduced here. The results and discussion are explained in Part 3. The conclusion is presented in the last part of this paper.

\section{Materials and Methods}

\subsection{Materials}

Chitosan with a deacetylation degree of $73 \%, 92.9 \%$, and $96 \%$ were obtained from the previous research [15]. Acetic acid, hydrochloric acid and lithium nitrate were purchased from Merck. Sodium hydroxide was purchased locally. De-ionized water was used in all experiments.

\subsection{Preparation of chitosan and chitosan- lithium dope solution}

The chitosan with variation of DD and molecular weight (MW) from deacetylation of $1 \times 3 \mathrm{~h}(\mathrm{DD}=73$ $\%$; MW $\left.=5.24 \times 10^{5} \mathrm{KDa}\right), 2 \times 3 \mathrm{~h}(\mathrm{DD}=92.9 \%$; $\left.\mathrm{MW}=2.8 \times 10^{5} \mathrm{KDa}\right)$ and $3 \times 3 \mathrm{~h}(\mathrm{DD}=96 \%$; MW $=2.5 \times 10^{5} \mathrm{KDa}$ ), were prepared to make chitosan dope solution with variation of $1 \%, 1.5 \%$ and $2 \%$. The chitosan dope solution of $1 \%$ was prepared from $1 \mathrm{~g}$ of chitosan was dissolved in $100 \mathrm{ml}$ of $2 \%$ acetic acid. The same procedure was used for the preparation of the chitosan dope solution of $1.5 \%$ and $2 \%$.

\subsection{Preparation of chitosan (CS) and chitosan-lithium (CS-Li) membranes}

The chitosan and chitosan-lithium dope solution were filtered by Buchner funnel and cast onto clean glass plate. The dope solutions were dried at room temperature for $72 \mathrm{~h}$. The chitosan membranes were neutralized by adding $1 \mathrm{~N}$ sodium hydroxide in the Petri dishes several times. Subsequently, the neutralized chitosan membranes were washed several times with deionized water. The chitosanlithium membranes neither washed by sodium hydroxide nor de-ionized water.

\subsection{Instrumentation}

Fourier transform infrared (FT-IR) spectroscopy (4,000-500 cm-1, resolution $\left.4 \mathrm{~cm}^{-1}\right)$, Scanning electron microscope (SEM), Impedance Analyzer (Agilent $\left.{ }^{\mathrm{TM}} \mathrm{E} 4980 \mathrm{~A}\right)$.

\subsection{Water uptake measurements}

The water uptake of membrane was determined by measuring the weight difference of membrane before and after immersion in water. Membrane samples dried at room temperature for $24 \mathrm{~h}$ were weighted, and the immersed in water at room temperature for $24 \mathrm{~h}$. After removing residual water on the surface membrane, the wet membrane was weighted. The water calculated based on Eq. 1 .

$$
\text { Water uptake }=\frac{M_{w e t}-M_{d r y}}{M_{d r y}} \times 100
$$

where $M_{\text {wet }}$ and $M_{\text {dry }}$ are the weights of the wet and dry membrane, respectively.

\subsection{Tensile strength measurements}

The tensile strength and breaking elongation of the membranes were directly obtained from the tensile tests. The elastic modulus (E) in $1 \%$ strain, the stress and strain at yield point and the stress and strain at break point, were directly obtained from the tensile stress elongation curves for each membrane sample. 


\subsection{Proton conductivity}

The membranes were cut to size of $12 \mathrm{~cm}^{2}$. Proton conductivity of fully hydrate membranes was measured as a function of temperature. Measurements were carried out in two points-probe conductivity cells using two platinum wire electrodes as working electrode. The electric resistance data were obtained using impedance analyzer (Aglient ${ }^{\mathrm{TM}}$ E4980A) and were recorded between $20 \mathrm{~Hz}-2 \mathrm{MHz}$ at working voltage amplitude of $1 \mathrm{~V}$. The impedance spectra were fitted on Z-View 2 software by Scribner Associates Inc. for curve fitting procedure. The proton conductivity values were obtained according to Eq. 2 .

$$
\sigma=\frac{S}{R \times A \times L}
$$

where $S$ is gap of electrodes, $A$ is wide of electrodes, $L$ is thickness of membrane and $R$ is membrane resistance derived from the low intersection of the high frequency semicircle on a complex impedance plane with $\operatorname{Re}(\mathrm{z})$ axis.

\subsection{Ion exchange capacity}

The membranes were cut to size of $3 \mathrm{~cm}^{2}$, then soaked in $50 \mathrm{ml}$ of $0.01 \mathrm{M}$ sodium hydroxide for 12 $\mathrm{h}$ at room temperature. A total of $10 \mathrm{ml}$ of sodium hydroxide solution was used for soaking the membrane was titrated by $0.01 \mathrm{M}$ hydrochloric acid with phenolphthalein indicator. In addition, $10 \mathrm{~mL}$ of $0.01 \mathrm{M}$ sodium hydroxide solution as a blank was also titrated with a solution of hydrochloric acid $0.01 \mathrm{M}$. Ion exchange capacity was calculated based on Eq.3 :

$$
I E C=\frac{\left(v_{\text {blanko }}-v_{\text {sampel }}\right) x[\text { base }] x f}{m}
$$

Where $\mathrm{v}$ is the volume, [base] is the concentration of the base, and $\mathrm{m}$ is the weight of the membrane.

\section{Results and Discussion}

\subsection{FT-IR analysis}

Fig. 1 shows FT-IR spectra of CS and CS-Li membranes. The characteristic band at $3446.6 \mathrm{~cm}^{-1}$, $2904.6 \mathrm{~cm}^{-1}, 1413.21 \mathrm{~cm}^{-1}$ and $1595.4 \mathrm{~cm}^{-1}$ are attributed to stretching of $\mathrm{O}-\mathrm{H}$ and $\mathrm{N}-\mathrm{H}$ amine, stretching $\mathrm{C}-\mathrm{H}$, stretching $\mathrm{C}-\mathrm{N}$ aliphatic amine and $\mathrm{N}-\mathrm{H}$ amide, respectively. The absorption of amide groups mean that chitosan is not all deacetylated. It is supported with chitosan deacetylation degree of $92.9 \%$.

The new peak appears at $1573.8 \mathrm{~cm}^{-1}$ for CS-Li membrane. It is attributed to ionic interaction between lithium salt with $\mathrm{NH}_{2}$ groups from chitosan. In addition, the peak of $\mathrm{N}-\mathrm{H}$ groups at $3446.56 \mathrm{~cm}^{-1}$ broaded to $3423.4 \mathrm{~cm}^{-1}$. Stretching vibration of C-H also shift to $2937.4 \mathrm{~cm}^{-1}$. Base on FT-IR data, the synthesis of chitosan and chitosanlithium was success.

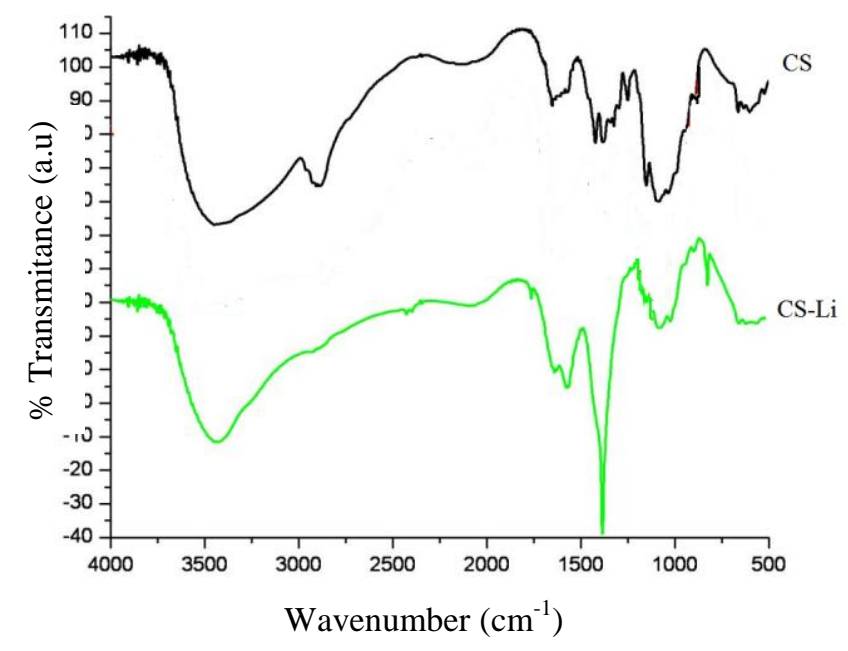

Fig. 1 FT-IR spectra of CS and CS-Li membranes

\subsection{SEM analysis}

SEM results (Fig. 2) show that CS membrane has high pore density. In addition, microstructure of CSlithium membrane has clusters that indicated lithium nitrate salts were deposited into chitosan polymer chains.

\subsection{Water uptake}

Chitosan membrane contains hydroxyl and amine groups. These groups are hydrophilic so that membranes can absorb water. Water uptake of CS and CS-Li membranes were shown in Table 1.

The results show that water uptake of CS membrane increase with increasing concentrations of chitosan as shown in Table 1 . The membrane with deacetylation time $2 \times 3$ hours has highest water uptake than $1 \times 3$ and $3 \times 3$ hours.

The water uptake of the CS-Li membranes was higher than that of the CS membrane. This is due to the crystalline nature of CS membrane that makes the water difficult to pass through the membrane. However, the presence of salt lithium nitrate bulky causes crystallinity of CS-Li membranes decrease 
and more hydrophilic than hydroxy groups on chitosan. Therefore, reducing the membrane crystallinity causes the increasing of the membrane hydrophility and produce greater water uptake. Water uptake of the CS-Li membranes are larger than the value of water uptake of PMM (polymethyl methacrylate) that reported by Luo et al. [3].

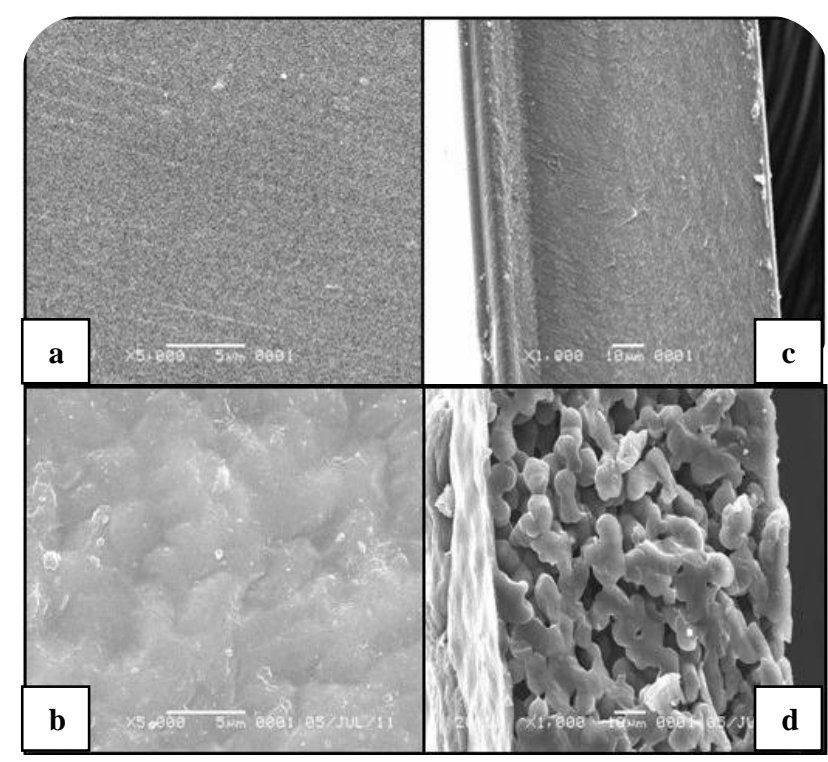

Fig. 2 Membranes microstructure : (a) CS membrane surface; (b) CS-Li membrane surface; (c) cross section of CS membrane; and (d) cross section of CS-Li membrane.

Table 1 Water uptake of CS and CS-Li membranes in various deacetylation time

\begin{tabular}{|c|c|c|c|}
\hline \multirow{2}{*}{$\begin{array}{c}\text { Deacetylation } \\
\text { time (h) }\end{array}$} & $\begin{array}{c}\text { Concentration } \\
\text { of chitosan } \\
(\%)\end{array}$ & \multicolumn{2}{|c|}{ \% Water uptake } \\
\cline { 3 - 4 } & 1 & 33.33 & - \\
\hline \multirow{3}{*}{$1 \times 3$} & 1.5 & 58.33 & - \\
\cline { 2 - 4 } & 2 & 64.29 & - \\
\hline \multirow{3}{*}{$2 \times 3$} & 1 & 94.74 & 400 \\
\cline { 2 - 4 } & 1.5 & 85.29 & 700 \\
\cline { 2 - 4 } & 2 & 67.86 & 870 \\
\hline \multirow{3}{*}{$3 \times 3$} & 1 & 54.54 & - \\
\cline { 2 - 4 } & 1.5 & 50.00 & - \\
\cline { 2 - 4 } & 2 & 71.42 & - \\
\hline
\end{tabular}

\subsection{Tensile Strength}

The mechanical strength of the CS and CS-Li membranes was determined by the tensile test such as the modulus of elasticity (E) (Young's modulus) and $\%$ elongation. The tensile test results are shown in Table 2.

Table 2 shows the increasing deacetylation time increased Young's modulus. The addition of lithium nitrate decreased the membrane strength. Moreover, the addition of lithium nitrate increased membrane elasticity, as shown in Fig. 3. Young's modulus of CS-Li membrane is in the range of Young's modulus value for lithium polymer battery that is at the level of 4000 - $650 \mathrm{Mpa}$ [16].

\subsection{Electrical conductivity}

Determination of the electrical conductivity is the main characteristics of the proton conductive membranes. Under normal circumstances, chitosan has low electrical conductivity. Although the structure monomer of chitosan has three hydrogen atoms, but hydrogen atoms are strongly bound to the framework so that chitosan can not be mobilized under the influence of an electric field to generate a proton conductor. However, if the chitosan dissolved in the acetic acid $\mathrm{H}^{+}$or $\mathrm{H}_{3} \mathrm{O}^{+}$and $\mathrm{CH}_{3} \mathrm{COO}^{-}$ions in the chitosan will be dispersed in the chitosan solvent and the ions can be mobilized under the influence of an electric field. If the $\mathrm{H}^{+}$or $\mathrm{H}_{3} \mathrm{O}^{+}$ions easier to move than $\mathrm{CH}_{3} \mathrm{COO}^{-}$then a layer of chitosan will be a proton conductor [7].

Table 2 Mechanical properties of CS and CS-Li membranes.

\begin{tabular}{|c|c|c|c|}
\hline Membranes & $\begin{array}{c}\text { Deacetylation } \\
\text { time (hours) }\end{array}$ & $\begin{array}{c}\text { Concentration } \\
\text { of chitosan } \\
(\%)\end{array}$ & $\mathrm{E}(\mathrm{Mpa})$ \\
\hline $\mathrm{CS}$ & $1 \times 3$ & 1 & 4153.3 \\
\hline & & 1.5 & 4337.4 \\
\hline & & 2 & 4540.7 \\
\hline & $2 \times 3$ & 1 & 2613.3 \\
\hline & & 1.5 & 2883.0 \\
\hline & & 2 & 3150.0 \\
\hline & $3 \times 3$ & 1 & 3013.4 \\
\hline & & 1.5 & 3081.0 \\
\hline & & 2 & 3839.9 \\
\hline $\mathrm{CS}-\mathrm{Li}$ & $2 \times 3$ & 1 & 2722.2 \\
\hline & & 1.5 & 2481.8 \\
\hline & & 2 & 2390.6 \\
\hline
\end{tabular}

The increasing of chitosan deacetylation time (DD) increases conductivity. Table 3 shows that chitosan membrane with deacetylation time $2 \times 3$ hour $(\mathrm{DD}=92.9 \%)$ has the largest conductivity. Deacetylation time $3 \times 3$ hour $(\mathrm{DD}=96 \%)$ has a 
lower conductivity than other chitosan membrane. It is addressed to lower molecular weight of the chitosan $\left(2.5 \times 10^{5} \mathrm{KDa}\right)$. Therefore, the physical appearance is wrinkled to membrane with chitosan deacetylation time $3 \times 3$ hour.

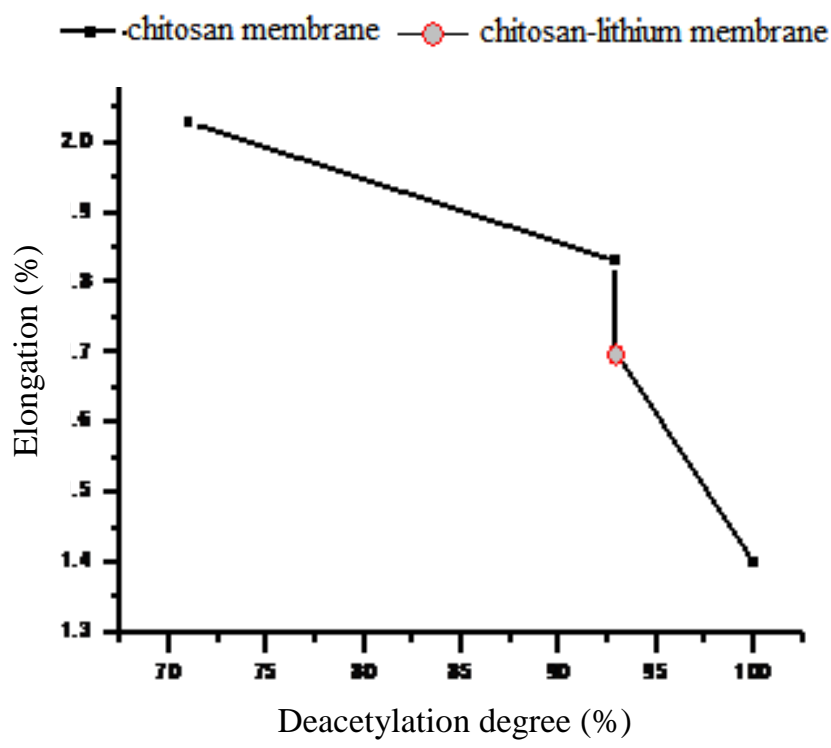

Fig. 3 Extension of CS membrane of $2 \%$ and CS-Li membrane of $2 \%$

Table 3 Conductivity of the CS and CS-Li membranes

\begin{tabular}{|c|c|c|c|}
\hline \multirow{2}{*}{$\begin{array}{c}\text { Deacetylation } \\
\text { time }(\mathrm{h})\end{array}$} & $\begin{array}{c}\text { Concentration } \\
\text { of chitosan } \\
(\%)\end{array}$ & \multicolumn{2}{|c|}{$\sigma\left(\mathrm{S}^{\mathrm{c}} \mathrm{cm} \mathrm{m}^{-1}\right)$} \\
\cline { 3 - 4 } & 1 & $\mathrm{CS}$ & $\mathrm{CS}-\mathrm{Li}$ \\
\hline \multirow{3}{*}{$1 \times 3$} & 1.5 & $1.1 \times 10^{-3}$ & - \\
\cline { 2 - 4 } & 2 & $1.2 \times 10^{-3}$ & - \\
\hline \multirow{3}{*}{$2 \times 3$} & 1 & $1.7 \times 10^{-2}$ & $2.2 \times 10^{-2}$ \\
\cline { 2 - 4 } & 1.5 & $1.6 \times 10^{-2}$ & $3.8 \times 10^{-2}$ \\
\cline { 2 - 4 } & 2 & $1.7 \times 10^{-3}$ & $8.5 \times 10^{-2}$ \\
\hline \multirow{3}{*}{$3 \times 3$} & 1 & $4.5 \times 10^{-7}$ & - \\
\cline { 2 - 4 } & 1.5 & $7.1 \times 10^{-4}$ & - \\
\cline { 2 - 4 } & 2 & $3.3 \times 10^{-3}$ & - \\
\hline
\end{tabular}

The conductivity value which generated from CS membrane was still lower than chitosan-lithium membrane. Presence lithium ion in CS-Li membrane can increase the conductivity. This result was also supported by the water uptake in the 3.3 subsection. Theoretically, decreasing the water uptake lead to decrease the proton conductivity, because the fewer water molecules in the membrane can be proton transfer media [17].

According to Wieczorek et al. [4], PMM electrolyte membrane that is commonly used in lithium polymer battery has a conductivity of $10^{-3}$ -
$10^{-2} \mathrm{~S}^{-\mathrm{cm}^{-1}}$. Therefore, the CS-Li of $2 \%$ with deacetylation time $2 \times 3$ hours (DD of $92.9 \%$ ) match this conductivity.

\subsection{Ion exchange capacity}

Ion exchange capacity (IEC) is the ability of the groups in the polymer to bind protons in the solution, thus indirectly shows proton conductivity of a polymer. In chitosan, ionic groups that support the activity of ion exchangers that group $-\mathrm{NH}_{3}{ }^{+}$. IEC of CS and CS-Li membranes were shown in Table 4.

The higher deacetylation time (higher DD) means large of $-\mathrm{NH}_{3}{ }^{+}$groups in chitosan which should increase ion exchange capacity. However, IEC of membrane with the deacetylation time $3 \times 3 \mathrm{~h}$ gave lower IEC. It is due to lower molecular weight of the membrane. The result also showed that the higher concentration of chitosan, the higher IEC.

Table 4 IEC value of CS and CS-Li membranes

\begin{tabular}{|c|c|c|c|}
\hline \multirow{2}{*}{$\begin{array}{c}\text { Deacetylation } \\
\text { time }(\mathrm{h})\end{array}$} & $\begin{array}{c}\text { Concentration } \\
\text { of chitosan } \\
(\%)\end{array}$ & \multicolumn{2}{|c|}{$\mathrm{IEC}\left(\mathrm{m}_{\mathrm{eq}} \cdot \mathrm{g}^{-1}\right)$} \\
\cline { 3 - 4 } & 1 & 1.11 & - \\
\hline \multirow{3}{*}{$1 \times 3$} & 1.5 & 1.45 & - \\
\cline { 2 - 4 } & 2 & 1.72 & - \\
\hline \multirow{3}{*}{$2 \times 3$} & 1 & 2.81 & 2.55 \\
\cline { 2 - 4 } & 1.5 & 2.76 & 2.59 \\
\cline { 2 - 4 } & 2 & 2.11 & 3.16 \\
\hline \multirow{3}{*}{$3 \times 3$} & 1 & 1.01 & - \\
\cline { 2 - 4 } & 1.5 & 1.09 & - \\
\cline { 2 - 4 } & 2 & 2.18 & - \\
\hline
\end{tabular}

\subsection{Application of CS-Li membrane in lithium polymer battery}

Testing of chitosan-lithium membranes in the application as a matrix battery lithium polymer were conducted by making a simple lithium polymer battery used battery electrode TCL Hyperpower. Simple battery made in the form of a sheet of chitosan membranes are squeezed in between two pieces of electrodes as shown in Fig. 4.

Test of battery capacity of circuit was also conducted to determine the current and voltage generated when the battery is used and after recharging process as shown in Fig. 5.

Based on Fig. 5, the voltage and electric current of simple battery was obtained using chitosan membrane that are $0.6 \mathrm{~A}$ and 0,006 volts, respectivelty for 1 layer membrane in the first second of the utilization of membranes in a simple 
battery. These values continue to decline during utilization and until the voltage or electric current to zero is obtained in 1287 seconds. This indicates that the capacity utilization after the battery has run time during the 1287 second. Utilization time of CS-Li membranes are still longer than PVDF membranes which were only able to produce electric current and voltage up to 989 seconds on a simple battery.

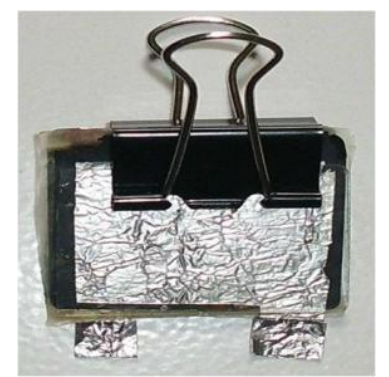

Fig. 4 A simple lithium polymer battery using chitosan membrane as electrolite matrix

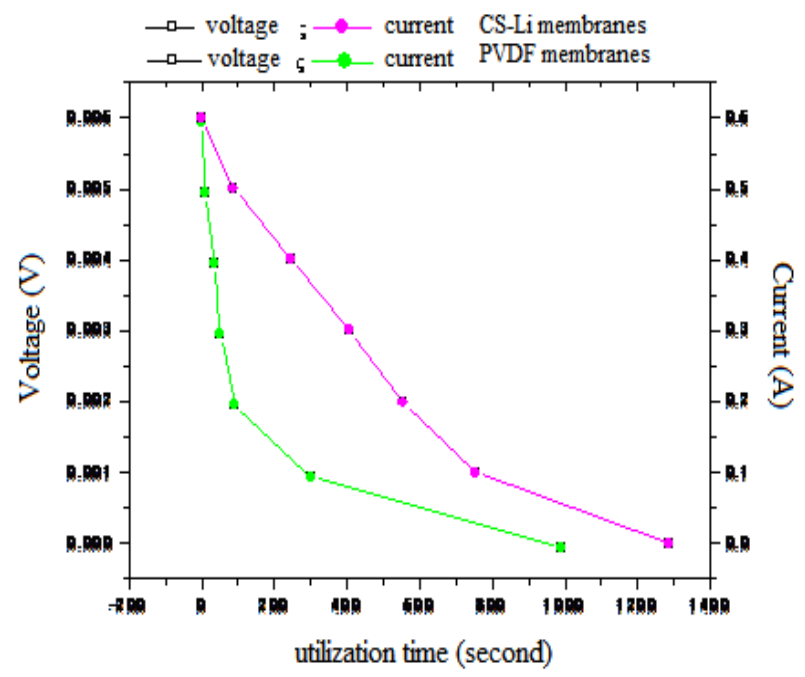

Fig. 5 Voltage and current of CS-Li membranes in utilization battery

Table 5. Data of voltage recharging of lithium polymer battery for CS-Li and PVDF

\begin{tabular}{|c|c|c|}
\hline \multirow{2}{*}{$\begin{array}{c}\text { Time } \\
\text { (second) }\end{array}$} & \multicolumn{2}{|c|}{ Charging the battery voltage (Volt) } \\
\cline { 2 - 3 } & CS-Li & PVDF [5] \\
\hline 0 & 0.04 & $1.3 \times 10^{-6}$ \\
\hline 30 & 0.70 & $15 \times 10^{-6}$ \\
\hline 60 & 1.30 & $2.1 \times 10^{-6}$ \\
\hline
\end{tabular}

Recharging is needed when the capacity of battery is zero. Based on Table 5, the capability rechargeable batteries obtained increase for every 30 second in voltage is \pm 0.70 volts. The results obtained are in accordance with PVDF polymer membrane that is used by commercial lithium batteries as a solid polymer electrolyte.

\section{Conclusion}

This study has presented an enhancement of conductivity and ion exchange capacity of chitosan membranes through modification with lithium. Membrane that was prepared with higher deacetylation time (higher DD) of chitosan generated higher conductivity and ion exchange capacity. Increasing chitosan concentration leads to increase ion conductivity of CS-Li membranes. In addition, adding Li ion increased conductivity and ion exchange capacity of the membrane. The result indicated that CS-Li membrane has a potential to be used as a polymer electrolyte in lithium battery.

This research has been successfully improved conductivity and ion exchange capacity chitosan membrane using chitosan prepared by repeated deacetylation instead of plasticizer. Nevertheless, it reduced the mechanical strength of the membrane as the use of plasticizers. The future direction of the research is to employ the membrane in the real lithium battery.

\section{References:}

[1] B. Y. Chang and S. M. Park, Electrochemical impedance spectroscopy, Annual Review of Analitycal Chemistry, Vol. 3, 2010, pp. 207229.

[2] W. H. Meyer, Polymer Electrolytes for Lithium-Ion Batteries, Max-Planck-Institut für Polymerforschung Ackermannweg 10, D55128 Mainz (Germany), 1998.

[3] Q. Luo, H. Zhang, J. Chen, P. Qian, and Y. Zhai, Modification of Nafion membrane using interfacial polymerization for vanadiumredox flow battery applications, Journal of Membrane Science, Vol. 311, 2008, pp. 98-103.

[4] W. Wieczorek, Z. Florjanczyk, G. Zukowska, R. Borkowska, P. Kuzma, E. ZygadloMonikowska, and K. Kuzwa, Ambient and subambient temperature proton-conducting polymer gel electrolytes, Solid State Ionics, Vol. 154, 2002, pp. 45-49.

[5] F. Ciuffa, F. Croce, A. D'Epifanio, S. Panero, and B. Scrosati, Lithium and proton conducting gel-type membranes, Journal of Power Sources, Vol. 127, 2004, pp. 53-57

[6] P. Mukoma, B. R. Jooste., and H. C. M. Vosloo, Synthesis and Characterization of Cross-Linked Chitosan Membranes for 
Application as Alternative Proton Exchange Membrane Materials in Fuel Cells, Journal of Power Sources, Vol. 136, 2004, pp. 16-23.

[7] N. S. Mohammed, R. H. Y. Subban, and A. K. Arof, Polymer Batteries Fabricated from Lithium Complexed Acetylated Chitosan, Journal of Power Sources, Vol. 56, 1995, pp. 153-156.

[8] I. Fauzi, I M. Arcana, and D. Wahyuningrum, Synthesis and Characterization of Solid Polymer Electrolyte from N-Succinyl Chitosan and Lithium Perchlorate, Advanced Materials Research, Vol. 896, 2014, pp. 58-61.

[9] Y. N. Sudhakar, M. Selvakumar, and D. Krishna Bhat, Ionics, Vol. 19, 2013, pp. 277285.

[10] M. Z. A. Yahya, A. M. M. Ali, M. F. Mohammat, and M. A. K. M. Hanafiah, Ionic Conduction Model in Salted Chitosan Membranes Plasticized with Fatty Acid, Journal of Applied Sciences, Vol. 6, 2006, pp. 1287-1291.

[11] S. N. S. Begum, R. Pandian, V. K. Aswal, and R. P. Ramasamy, Chitosan-Gold-Lithium Nanocomposites as Solid Polymer Electrolyte, Journal of Nanoscience and Nanotechnology, Vol. 14, 2014, pp. 5761-5773.

[12] N. A. A. Razak, T. Winie, F. S. A. Ghani, and A. H. Ahmad, Conductivity and FTIR Studies on PVA/Chitosan- $\mathrm{LiCF}_{3} \mathrm{SO}_{3}, \quad$ Solid State Science and Technology, Vol. 16, 2008, pp. 17.

[13] S. Fuente, P. J. Retuert, and G. Gonzalez, Lithium Ion Conductivity of Molecularly Compatibilized chitosan-poly (aminopropyltriethoxysilane)-poly(ethylene oxide) nanocomposites, Electrochimica Acta, Vol. 53, 2007, pp. 1417-1421.
[14] L. O. A. N. Ramadhan, C. L. Radiman., D. Wahyuningrum, V. Suendo, L. O. Ahmad, and S. Valiyaveetill., Deasetilasi Kitin secara Bertahap dan Pengaruhnya terhadap Derajad Deasetilasi serta Massa Molekul Kitosan, Jurnal Kimia Indonesis, Vol. 5 (1), 2010, pp. 17-21.

[15] Wahab, L. O. A. N. Ramadhan, L. O. Ahmad, S. H. Sabarwati, and D. Permana, Preparation of Chitosan from Windu Shrimp Shell Waste Collected at Ocean Harbour of Kendari with Three Stages Deacetylation Method, Celebes International Conference on Diversity at Wallacea's Line 2015 (CICDWL 2015) Proceedings, Universitas Halu Oleo, pp. 368373.

[16] A. Magasinski, B. Zdyrko, I. Kovalenko, B. Hertzberg, R. Burtovyy, C. F. Huebner, T. F. Fuller, I. Luzinov, and G. Yushin, Toward Efficient Binders for Li-Ion Battery Si-Based Anodes: Polyacrylic Acid, ACS Applied Materials and Interfaces, Vol. 2, 2010, pp. 3004-3010.

[17] K. D. Kreuer, On the Development of Proton Conducting Polymer Membranes for Hydrogen and Methanol Fuel Cells, Journal of Membrane Science, Vol. 185, 2001, pp. 29-39. 